\title{
Open-shell jellium aromaticity in metal clusters
}

\author{
Jordi Poater*ab and Miquel Solà*c
}

Received 00th January 20xx,

Accepted 00th January 20xx

DOI: $10.1039 / \times 0 \times x 00000 x$

The $2 N^{2}+2 N+1$ with $S=N+1 / 2$ rule represented the extension to open-shell spherical compounds of the $2(N+1)^{2}$ Hirsch rule for spherical aromatic species. In this work, we provide evidences that the jellium model with its magic numbers can be also extended to open-shell half-filled systems.

Many of the archetypal aromatic molecules such as benzene, $\mathrm{Al}_{4}{ }^{-2}$ or $\mathrm{B}_{6} \mathrm{H}_{6}{ }^{-2}$ present high symmetry and possess degenerate highest-occupied molecular orbitals. ${ }^{1-3}$ These orbitals are fully occupied resulting in a closed-shell structure that provides an extra stabilization to the system, similar to the situation found in noble gas elements. Annulenes with a closed-shell structure are an example of this type of electronic structure. For these species, except for the most stable and unstable $\pi$-orbitals, the rest of the $\pi$-molecular orbitals of annulenes with an even number of $\mathrm{C}$ atoms are grouped in pairs of degenerate orbitals. With this particular distribution of the $\pi$-molecular orbitals a closed-shell electronic structure is reached with $4 \mathrm{~N}+2 \pi-$ electrons resulting in the renowned Hückel's rule. ${ }^{4-7}$ An analogous situation is found for the spherical compounds that obey Hirsch's $2(\mathrm{~N}+1)^{2}$ rule of aromaticity. ${ }^{8,9}$ According to this rule, icosahedral $\mathrm{C}_{20}+2, \mathrm{C}_{60}+10$ or $\mathrm{C}_{80}+8$ are aromatic fullerenes.

The degenerate highest-occupied molecular orbitals can also be same-spin half-filled and the resulting species have an open-shell structure that also provides an extra stabilization to the system. In the case of annulenes, this electronic structure is reached for the lowest-lying triplet of $4 \mathrm{~N} \pi$-electrons. This $4 \mathrm{~N} \pi$ electron rule was formulated by Baird in $1972 .{ }^{10}$ He showed that annulenes which are aromatic in their singlet ground state are antiaromatic in their lowest-lying triplet state and vice versa for annulenes that are antiaromatic in the ground state. ${ }^{11}$ Following this line of reasoning, we suggested that spherical compounds

a. Departament de Química Inorgànica i Orgànica \& Institut de Química Teòrica Computacional (IQTCUB), Universitat de Barcelona, Martí $i$ Franquès 1-11, 08028 Barcelona, Catalonia, Spain.E-mail: Jordi.poater@ub.edu

b.ICREA, Pg. Lluís Companys 23, 08010 Barcelona, Spain.

c. Institut de Química Computacional i Catàlisi and Departament de Química, Universitat de Girona, C/ Maria Aurèlia Capmany, 69, 17003 Girona, Catalonia, Spain.E-mail:miquel.sola@udg.edu

+Electronic Supplementary Information (ESI) available: Cartesian coordinates of all species, valence orbital energies, computational details and atomization energies per atom of Na clusters. See DOI: 10.1039/x0xx00000x having a same-spin half-filled last energy level with the rest of the levels being full filled should be also aromatic. Indeed, we showed that this situation is reached for a number of electrons equal to $2 \mathrm{~N}^{2}+2 \mathrm{~N}+1$ with $\mathrm{S}=\mathrm{N}+1 / 2$ and we proved that, among others, $C_{60}{ }^{-1}$ with $S=11 / 2$ or $C_{80} 0^{-5}$ species with $S=13 / 2$ are aromatic fullerenes. ${ }^{12}$

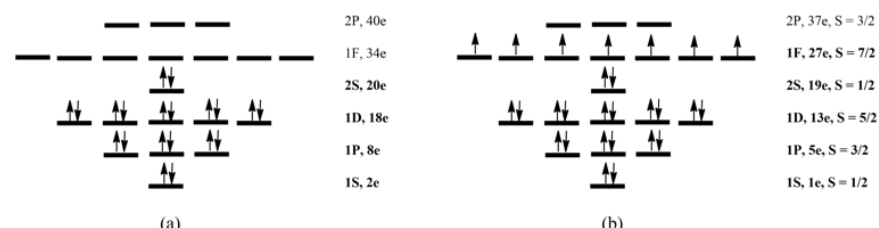

Scheme 1. The (a) closed-shell and (b) open-shell jellium magic numbers. In this Scheme, we have depicted the occupancies of a system with $20 \mathrm{e}$ - for the closed-shell and of $27 \mathrm{e}$ - for the open-shell electronic structure.

A cluster is an ensemble of bound atoms or molecules that is intermediate in size between an atom or a molecule and a bulk solid. ${ }^{13,14}$ Atomic clusters can be either pure, formed from a single atomic species (e.g. silver nanoparticles), or mixed, formed from several atomic species (e.g. titanium oxide nanoparticles). The observed experimental abundances of a number of metal clusters have been successfully explained with the spherical jellium model. This model assumes a uniform distribution of positive charge corresponding to the cluster atomic nuclei and their innermost electrons in which the interacting valence electrons move. The energy levels of valence electrons for such a model are $1 S^{2} 1 P^{6} 1 D^{10} 2 S^{2} 1 F^{14} 2 P^{6} 1 G^{18} 2 D^{10} 3 S^{2} \ldots$ (see Scheme 1 ), where $S, P$, $D, F$, and $G$ letters denote the angular momentum and numbers $1,2,3$ indicate the radial nodes. ${ }^{15-18}$ The abundance found in experimental mass spectra of alkali, alkaline earth metals, and gold clusters of $2,8,18,20,34,40 \ldots$ atoms are justified taken into account that these numbers correspond to closed-shell electronic structures in the jellium model. ${ }^{16,19-22}$ These magic numbers explain also the abundance of other all-metal or heteroatomic clusters such as $\mathrm{Al}_{13},{ }^{-23,}{ }^{24} \mathrm{Si}_{4} \mathrm{Mg}_{3},{ }^{25} \mathrm{Si}_{x} \mathrm{Ge}_{y} \mathrm{M}^{+}(\mathrm{x}+$ $y=4, M=N b, T a),{ }^{26} \mathrm{Mg}_{17},{ }^{27}$ among others. ${ }^{28}$ It is worth noting 
that based on the jellium rule a series of superatoms have been designed. ${ }^{29}$ In previous work, it has been shown that some of these closed-shell atomic clusters are aromatic. ${ }^{18}$ It is worth noting that there is an important difference between the spherical aromaticity and the jellium aromaticity, namely, whereas the aromaticity of spherical compounds is due to delocalization of electrons on the surface of the sphere, the jellium aromaticity is generated by the delocalization of electrons inside the metal cluster.

In this work, we explore whether the Baird and the $2 \mathrm{~N}^{2}+2 \mathrm{~N}$ +1 with $S=N+1 / 2$ rules can be extended to atomic clusters. If the last energy level of valence electrons for the jellium model is half-filled with same-spin electrons, the system should have some extra stability and should have aromatic character. As seen in Scheme 1, this situation is reached for the magic numbers of valence electrons of $1(\mathrm{~S}=1 / 2), 5(\mathrm{~S}=3 / 2), 13(\mathrm{~S}=$ $5 / 2), 19(S=1 / 2), 27(S=7 / 2), 37(S=3 / 2), 49(S=9 / 2) \ldots$ Apparently, this is the case for $\mathrm{Li}_{6}{ }^{+}(\mathrm{S}=3 / 2)$ with 5 valence electrons. ${ }^{30}$ Interestingly, $\mathrm{Li}_{6}{ }^{+}(\mathrm{S}=3 / 2)$ follows both the $2 \mathrm{~N}^{2}+2 \mathrm{~N}$ +1 with $S=N+1 / 2$ and the open-shell jellium rules. We consider different clusters of sodium and beryllium of small to medium size to check this hypothesis. Of course, the closer the cluster to a spherical geometry, the higher the probability that the cluster may obey the open-shell jellium rule.

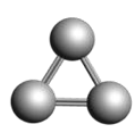

$\mathrm{Be}_{3}{ }^{+1}$

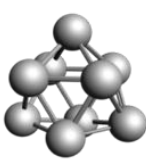

$\mathrm{Be}_{9}{ }^{-1}$

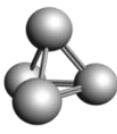

$\mathrm{Be}_{4}$

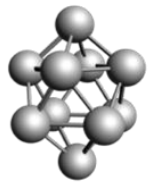

$\mathrm{Be}_{10}{ }^{+1}$

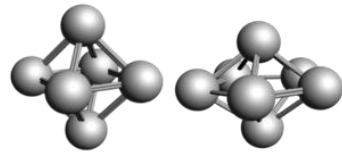

$\mathrm{Be}_{6}{ }^{-1}$

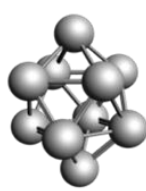

$\mathrm{Be}_{10}$
$\mathrm{Be}_{7}^{+1}$

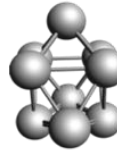

$\mathrm{Be}_{9}$

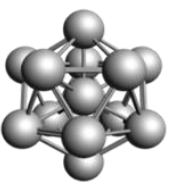

$\mathrm{Be}_{13}{ }^{-1}$

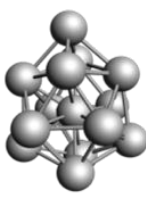

$\mathrm{Be}_{14}{ }^{+1}$
Scheme 2 Geometries of the beryllium clusters under analysis.

We first focus on ten beryllium clusters (Scheme 2 and Table 1), $\mathrm{Be}_{4}, \mathrm{Be}_{9}$, and $\mathrm{Be}_{10}$ are closed-shell systems, whereas $\mathrm{Be}_{3}{ }^{+1}$, $\mathrm{Be}_{6}^{-1}, \mathrm{Be}_{7}^{+1}, \mathrm{Be}_{9}^{-1}, \mathrm{Be}_{10^{+1}}, \mathrm{Be}_{13^{-1}}$, and $\mathrm{Be}_{14}^{+1}$ follow the open-shell jellium model with a same spin half-filled last energy level. All open-shell species are in their ground state, except for $\mathrm{Be}_{3}{ }^{+1}$ for which the doublet state is $9.7 \mathrm{kcal} \mathrm{mol}^{-1}$ more stable than its quadruplet and $\mathrm{Be}_{6}{ }^{-1}$ with a quadruplet that is $23.8 \mathrm{kcal} \mathrm{mol}^{-1}$ more stable than its sextuplet. The result for $\mathrm{Be}_{3}{ }^{+1}$ could be expected because its geometry is far from being spherical. Some clusters, for instance, $\mathrm{Be}_{6}{ }^{-1}$ and $\mathrm{Be}_{7}^{+1}$, have the same electronic structure (both have the last energy level half-filled with 5 electrons) but different molecular structure. Open-shell systems present the expected almost degenerate molecular orbitals in the last half-filled energy level (see Table S3 in the ESI). The more spherical the geometry, the closer to a perfect degeneracy. All studied beryllium clusters are clearly aromatic according to NICS and $\mathrm{MCl}$ criteria. For comparison, $\mathrm{Be}_{13}{ }^{-1}$, with 7 unpaired electrons half-filling the last energy level, presents an averaged $\mathrm{NICS}(0)_{\mathrm{zz}}$ of $-40.5 \mathrm{ppm}$, an averaged $\mathrm{MCl}$ of 0.124 e., a BLA of only $10.8 \mathrm{mẢ}$, an atomization energy of $2.01 \mathrm{eV}$ and In symmetry, all criteria fully supporting its aromaticity. Although average $\mathrm{MCl}$ and $\mathrm{NICS}(0)_{z z}$ are local aromaticity measures, the result obtained in these particular clusters is the result of the presence of a global aromaticity. This latter is proven by $\operatorname{NICS}(0)_{z z}$ calculated in the centre of the clusters (only for the clusters that do not have an atom in the centre), also enclosed in Table 1, which follow the same trend as the averaged ones.

Table 1 Beryllium clusters under analysis, including the symmetry, the spin, the $\operatorname{NICS}(0)_{z z}$ (in ppm), the $\mathrm{MCl}$ (in e.), the BLA (in mÅ), and the atomization energy per atom $\Delta \mathrm{E}_{\text {atom }}$ (in eV).

\begin{tabular}{|c|c|c|c|c|c|c|}
\hline & Symm. & Spin & $\operatorname{NICS}(0)_{z z}^{a}$ & $\mathrm{MCl}^{\mathrm{a}}$ & BLA $^{b}$ & $\Delta \mathrm{E}_{\text {atom }}$ \\
\hline $\mathrm{Be}_{3}{ }^{+1 \mathrm{c}}$ & $\mathrm{D}_{3 \mathrm{~h}}$ & $3 / 2$ & -34.4 & 0.466 & 0.0 & 0.95 \\
\hline $\mathrm{Be}_{4}$ & $\mathrm{~T}_{\mathrm{d}}$ & 0 & $\begin{array}{r}-46.5 \\
(-46.5)\end{array}$ & 0.291 & 0.0 & 1.04 \\
\hline $\mathrm{Be}^{-1 \mathrm{c}}$ & $\mathrm{D}_{4 \mathrm{~h}}$ & $5 / 2$ & $\begin{array}{r}-50.5 \\
(-63.4)\end{array}$ & 0.131 & 13.0 & 1.35 \\
\hline $\mathrm{Be}_{7}^{+1}$ & $D_{5 h}$ & $5 / 2$ & $\begin{array}{r}-34.1 \\
(-49.8)\end{array}$ & 0.099 & 10.0 & 1.67 \\
\hline $\mathrm{Be}_{9}$ & $\mathrm{D}_{3 \mathrm{~h}}$ & 0 & $\begin{array}{r}-41.9 \\
(-59.4)\end{array}$ & 0.138 & 16.2 & 1.63 \\
\hline $\mathrm{Be}_{9}^{-1}$ & $\mathrm{D}_{3 \mathrm{~h}}$ & $1 / 2$ & $\begin{array}{r}-43.3 \\
(-66.0)\end{array}$ & 0.026 & 15.1 & 1.94 \\
\hline $\mathrm{Be}_{10}^{+1}$ & $D_{4 d}$ & $1 / 2$ & $\begin{array}{r}-42.8 \\
(-57.1)\end{array}$ & 0.110 & 15.2 & 2.03 \\
\hline $\mathrm{Be}_{10}$ & $\mathrm{D}_{4 \mathrm{~d}}$ & 0 & $\begin{array}{r}-48.7 \\
(-64.3)\end{array}$ & 0.113 & 16.7 & 1.79 \\
\hline $\mathrm{Be}_{13^{-1}}$ & $\mathrm{Ih}_{\mathrm{h}}$ & $7 / 2$ & -40.5 & 0.124 & 10.8 & 2.01 \\
\hline $\mathrm{Be}_{14}{ }^{+1}$ & $\mathrm{C}_{2}$ & $7 / 2$ & -36.8 & 0.088 & 42.1 & 1.99 \\
\hline
\end{tabular}

a Averaged $\mathrm{NICS}(0)_{\mathrm{zz}}$ and $\mathrm{MCl}$ of all rings of the surface of the cluster; and $\operatorname{NICS}(0)_{z z}$ in the centre of the cluster in parentheses. ${ }^{b}$ Difference between longest and shortest $\mathrm{Be} \cdots$ Be bond lengths. ${ }^{\mathrm{C}} \mathrm{Be}_{3}{ }^{+1}$ doublet is $9.7 \mathrm{kcal} \mathrm{mol}^{-1}$ more stable than its quadruplet; whereas $\mathrm{Be}_{6}{ }^{-1}$ quadruplet is $23.8 \mathrm{kcal} \mathrm{mol}^{-1}$ more stable than its sextuplet.

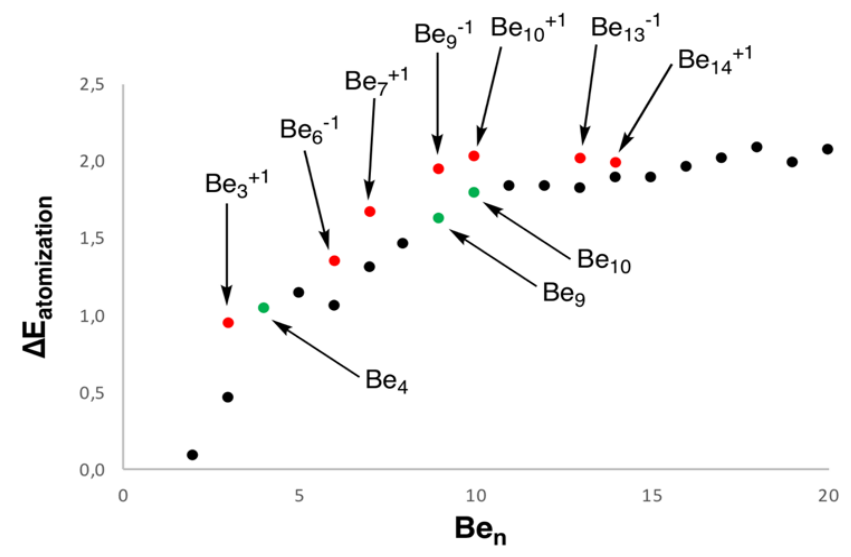

Fig. 1 Atomization energies per atom (in eV) of the neutral $\mathrm{Be}_{\mathrm{n}}$ clusters with $n=2-20$ (in black). Beryllium clusters that follow the open-shell jellium model in red; closed-shell clusters obeying the jellium model in green $\left(\mathrm{Be}_{4}, \mathrm{Be}_{9}\right.$, and $\left.\mathrm{Be}_{10}\right)$; the rest in black. 
Another important measure of the stability of the beryllium clusters is the atomization energy per atom $\left(\Delta \mathrm{E}_{\text {atom, }}\right.$, Table 1 , Fig. 1 ). For a given cluster, the larger the atomization energy, the higher its stability. As observed in Fig. 1, the atomization energy increases with the size of the Be cluster (Fig. 1, dots in black), as previously stated by Cerowski et al. ${ }^{20}$ In case of those Be clusters following the open-shell jellium model (Fig. 1, dots in red), their atomization energy values are larger than for their neutral equivalent clusters, these latter not following the jellium model (except for $\mathrm{Be}_{4}, \mathrm{Be}_{9}$, and $\mathrm{Be}_{10}$ ). For instance, the $\Delta \mathrm{E}_{\text {atom }}$ for $\mathrm{Be}_{6}{ }^{-1}$ is $1.35 \mathrm{eV}$, whereas that for $\mathrm{Be}_{6}$ is $1.05 \mathrm{eV}$; or that for $\mathrm{Be}_{7}^{+1}$ is $1.67 \mathrm{eV}$, whereas $\mathrm{Be}_{7}$ presents an $\Delta \mathrm{E}_{\text {atom }}=1.31 \mathrm{eV}$. This trend is followed by all Be clusters with magic numbers of electrons according to the open-shell jellium model, thus also proving their larger stability.

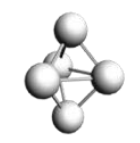

$\mathrm{Na}_{5}$

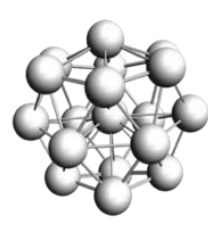

$\mathrm{Na}_{18}$

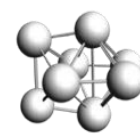

$\mathrm{Na}_{8}$

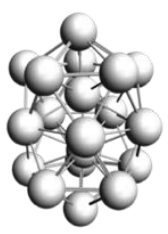

$\mathrm{Na}_{19}$

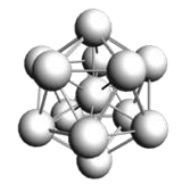

$\mathrm{Na}_{13}$

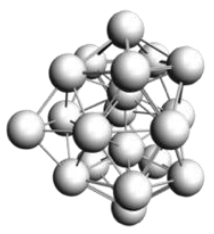

$\mathrm{Na}_{20}$
Scheme 3. Geometries of the sodium clusters under analysis enclosed in Table 1.

Next we analyse a series of six sodium clusters (Scheme 3 and Table 2), three of them closed-shell singlets with the last energy level fully-filled $\left(\mathrm{Na}_{8}, \mathrm{Na}_{18}\right.$, and $\left.\mathrm{Na}_{20}\right)$ and three of them open-shell with the last energy level half-filled with same-spin electrons $\left(\mathrm{Na}_{5}, \mathrm{Na}_{13}\right.$, and $\left.\mathrm{Na}_{19}\right)$. It is worth noting that the quintuplet state for $\mathrm{Na}_{13}$ and the doublet state for $\mathrm{Na}_{19}$ are the ground states for these clusters, showing the particular stability of these half-filled open-shell jellium systems. However, for $\mathrm{Na}_{5}$, which is a less spherical cluster than $\mathrm{Na}_{13}$, and $\mathrm{Na}_{19}$, the doublet is $6.3 \mathrm{kcal} / \mathrm{mol}$ more stable than the quadruplet. Open-shell systems present the expected almost degenerate molecular orbitals in the last half-filled energy level (see Table S3 in the $\mathrm{ESI}$ ). Magnetic $\mathrm{NICS}(0)_{\mathrm{zz}}$ and electronic $\mathrm{MCl}$ aromaticity criteria state that the clusters following the open-shell jellium model are also aromatic, at least as much as the closed-shell ones (Table 2). For instance, in case of $\mathrm{Na}_{13}$, with a spin of $5 / 2$ (5 unpaired electrons in the last level), the averaged $\operatorname{NICS}(0)_{z z}$ is $28.0 \mathrm{ppm}$, whereas the averaged $\mathrm{MCl}$ is 0.034 e., the aromaticity of this cluster being supported by both criteria. This result is reinforced by the geometric BLA criterion, with quite small values for all clusters under analysis. As to the atomization energy (Fig. S1 in the $\mathrm{SI}$ ), it increases with the size of the cluster being comparable for clusters of the similar size irrespective if they are clusters with closed- or half-filled open-shell jellium electronic structures.

Table 2 Sodium clusters under analysis, including the symmetry, the

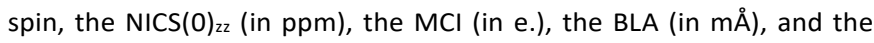
atomization energy per atom $\Delta \mathrm{E}_{\text {atom }}$ (in $\mathrm{eV}$ ).

\begin{tabular}{|c|c|c|c|c|c|c|}
\hline & Symm. & Spin & $\operatorname{NICS}(0)_{z z}{ }^{a}$ & $\mathrm{MCl}^{\mathrm{a}}$ & BLA $^{b}$ & $\Delta E_{\text {atom }}$ \\
\hline $\mathrm{Na}_{5}{ }^{\mathrm{c}}$ & $D_{3 h}$ & $3 / 2$ & $\begin{array}{r}-16.5 \\
(-19.1)\end{array}$ & 0.076 & 50.8 & 0.34 \\
\hline $\mathrm{Na} 8$ & $D_{2 d}$ & 0 & $\begin{array}{r}-20.5 \\
(-26.3)\end{array}$ & 0.062 & 39.2 & 0.57 \\
\hline $\mathrm{Na}_{13}$ & $I_{h}$ & $5 / 2$ & -28.0 & 0.034 & 18.1 & 0.55 \\
\hline $\mathrm{Na}_{18}$ & $\mathrm{C}_{2 \mathrm{v}}$ & 0 & -31.1 & 0.049 & 76.7 & 0.63 \\
\hline $\mathrm{Na}_{19}$ & $\mathrm{C}_{1}$ & $1 / 2$ & -32.0 & 0.023 & 83.1 & 0.63 \\
\hline $\mathrm{Na}_{20}$ & $C_{2 v}$ & 0 & -31.8 & 0.043 & 65.0 & 0.64 \\
\hline
\end{tabular}

a Averaged $\mathrm{NICS}(0)_{z z}$ and $\mathrm{MCl}$ of all rings of the surface of the cluster; and $\operatorname{NICS}(0)_{z z}$ in the centre of the cluster in parentheses. ${ }^{b}$ Difference between longest and shortest $\mathrm{Na} \cdots \mathrm{Na}$ bond lengths. ${ }^{\mathrm{C}} \mathrm{Na}{ }_{5}$ doublet is 6.3 kcal mol-1 more stable than its quadruplet.

As a whole, we have proven that the Baird and the $2 \mathrm{~N}^{2}+2 \mathrm{~N}$ +1 with $\mathrm{S}=\mathrm{N}+1 / 2$ rules can be extended to atomic clusters. In particular, those clusters whose last energy level of valence electrons is half-filled with same-spin electrons in the jellium electronic structure are aromatic and present an extra stability compared to those that do not accomplish such rule, as proven by their larger atomization energy. This new set of magic numbers may become a powerful tool for researchers who work in the quest for stable single high-spin molecules for their use as single-molecule based magnets. ${ }^{31-34}$

This work has been supported by the Ministerio de Economía y Competitividad (MINECO) of Spain (Projects CTQ2017-85341-P, CTQ2016-77558-R, and MDM-2017-0767) and the Generalitat de Catalunya (projects 2017SGR39 and 2017SGR348, and ICREA Academia 2014 prize for M.S.). Excellent service by the Supercomputer center of the Consorci de Serveis Universitaris de Catalunya (CSUC) is gratefully acknowledged.

\section{Conflicts of interest}

There are no conflicts to declare.

\section{Notes and references}

¥ Geometry optimizations without symmetry constraints and calculations of $\mathrm{MCl}$ and $\mathrm{NICS}(0)$ indices were performed with the Gaussian $09^{35}$ and ESI-3D $36-38$ packages of programs at the B3LYP/6-31G* level of theory. ${ }^{39}$, 40 Characterization of the stationary points was carried out by analytical frequency calculations. All presented geometries are minima. In all cases, we report the most stable minima found for each cluster. Although we tried different initial molecular structures for the optimization of each cluster, we cannot fully guarantee that the minima found are the global minima. NICS(0) values have been computed through the gauge-including atomic orbital method (GIAO) 
implemented in Gaussian 09. The magnetic shielding tensor has been calculated for ghost atoms located at the atomic cluster/ring centres determined by the non-weighted mean of the heavy atoms coordinates. Both $\mathrm{NICS}(0)_{z z}$ and $\mathrm{MCl}$ have been calculated as the average of all three-member rings of the clusters. The atomization energy per atom has been calculated as the energy corresponding to these reactions: $[\mathrm{Na}]_{n} \rightarrow \mathrm{nNa}$ or $[\mathrm{Be}]_{n} \rightarrow \mathrm{nBe}$. In case or anionic or cationic clusters, the atomic energy of $\mathrm{Be}^{-}$or $\mathrm{Be}^{+}$has been considered. On the other hand, the bond length alternation (BLA) is calculated as the difference between the longest and shortest bond length between two connected atoms in a cluster.

1.

M. Solà, in Encyclopedia of Physical Organic Chemistry, ed. Z. Wang, John Wiley \& Sons, Weinheim, 2017, vol. 6, pp. 511-542.

2.

F. Feixas, E. Matito, J. Poater and M. Solà, in Applications of Topological Methods in Molecular Chemistry, eds. E. Alikhani, R. Chauvin, C. Lepetit and B. Silvi, Springer, Berlin, 2016, vol. 22, ch. 12, pp. 321-336.

3. M. Solà, WIREs Comput. Mol. Sci., 2019, 9, DOI: 10.1002/wcms.1404.

4.

5.

6.

7.

8.

9.

10.

11

12.

13

E. Hückel, Z. Physik, 1931, 70, 104-186.

E. Hückel, Z. Physik, 1931, 72, 310-337.

E. Hückel, Z. Physik, 1932, 76, 628-648.

E. Hückel, Z. Elektrochemie, 1937, 43, 752-788, 827-849.

A. Hirsch, Z. Chen and H. Jiao, Angew. Chem. Int. Ed., 2000, 39, 3915-3917.

A. Hirsch, Z. Chen and H. Jiao, Angew. Chem. Int. Ed., 2001, 40, 2834-2838.

N. C. Baird, J. Am. Chem. Soc., 1972, 94, 4941-4948.

H. Ottosson, Nat. Chem., 2012, 4, 969-971.

J. Poater and M. Solà, Chem. Commun., 2011, 47, 1164711649.

S. A. Claridge, A. W. Castleman, S. N. Khanna, C. B. Murray, A. Sen and P. S. Weiss, ACS Nano, 2009, 3, 244-255.

14. A. W. Castleman and S. N. Khanna, J. Phys. Chem. C, 2009, 113, 2664-2675.

15. W. Ekardt, Phys. Rev. B, 1984, 29, 1558-1564.

16. M. L. Cohen, M. Y. Chou, W. D. Knight and W. A. De Heer, J. Phys. Chem., 1987, 91, 3141-3149.

17. W. A. de Heer, Rev. Mod. Phys., 1993, 65, 611-676.

18. T. Höltzl, T. Veszprémi, P. Lievens and M. T. Nguyen, in Aromaticity and Metal Clusters, ed. P. K. Chattaraj, CRC Press, Boca Raton, 2010, ch. 14, pp. 271-296.

19. W. D. Knight, K. Clemenger, W. A. de Heer, W. A. Saunders, M. Y. Chou and M. L. Cohen, Phys. Rev. Lett., 1984, 52, 2141-2143.

20. V. Cerowski, B. K. Rao, S. N. Khanna, P. Jena, S. Ishii, K. Ohno and Y. Kawazoe, J. Chem. Phys., 2005, 123, 074329.

21. M. Walter, J. Akola, O. Lopez-Acevedo, P. D. Jadzinsky, G. Calero, C. J. Ackerson, R. L. Whetten, H. Grönbeck and H. Häkkinen, Proc. Nat. Acad. Sci., 2008, 105, 9157-9162.

22. S. Kümmel, M. Brack and P. G. Reinhard, Phys. Rev. B, 2000, 62, 7602-7613.

23. D. E. Bergeron, A. W. Castleman, T. Morisato and S. N. Khanna, Science, 2004, 304, 84-87.

$24 . \quad$ T. Kambe, N. Haruta, T. Imaoka and K. Yamamoto, Nature Commun., 2017, 8, 2046.

$25 . \quad$ D. R. Roy, J. Nano Res., 2013, 24, 77-84.

26. L. Xiaojun, Y. Zhijun and L. Shuna, J. Comput. Chem., 2016, 37, 2316-2323.
27. X. Xia, X. Kuang, C. Lu, Y. Jin, X. Xing, G. Merino and A. Hermann, J. Phys. Chem. A, 2016, 120, 7947-7954.

28. C. E. Jones, P. A. Clayborne, J. U. Reveles, J. J. Melko, U. Gupta, S. N. Khanna and A. W. Castleman, J. Phys. Chem. A, 2008, 112, 13316-13325.

29. W.-M. Sun, X.-L. Zhang, K.-Y. Pan, J.-H. Chen, D. Wu, C.-Y. Li, Y. Li and Z.-R. Li, Chem. Eur. J., 2019, 25, 4358-4366.

30. O. El Bakouri, V. Postils, M. Garcia-Borràs, M. Duran, J. M. Luis, S. Calvello, A. Soncini, E. Matito, F. Feixas and M. Solà, Chem. Eur. J., 2018, 24, 9853-9859.

31. G. Christou, D. Gatteschi, D. N. Hendrickson and R. Sessoli, MRS Bull., 2000, 25, 66-71.

32. C. A. P. Goodwin, F. Ortu, D. Reta, N. F. Chilton and D. P. Mills, Nature, 2017, 548, 439.

33. B. M. Day, F.-S. Guo and R. A. Layfield, Acc. Chem. Res., 2018, 51, 1880-1889.

34. J. Long, Front. Chem., 2019, 7, 63.

35. M. J. Frisch, G. W. Trucks, H. B. Schlegel, G. E. Scuseria, M. A. Robb, J. R. Cheeseman, G. Scalmani, V. Barone, B. Mennucci, G. A. Petersson, H. Nakatsuji, M. Caricato, X. Li, H. P. Hratchian, A. F. Izmaylov, J. Bloino, G. Zheng, J. L. Sonnenberg, M. Hada, M. Ehara, K. Toyota, R. Fukuda, J. Hasegawa, M. Ishida, T. Nakajima, Y. Honda, O. Kitao, H. Nakai, T. Vreven, J. A. Montgomery Jr., J. E. Peralta, F. Ogliaro, M. Bearpark, J. J. Heyd, E. Brothers, K. N. Kudin, V. N. Staroverov, R. Kobayashi, J. Normand, K. Raghavachari, A. Rendell, J. C. Burant, S. S. Iyengar, J. Tomasi, M. Cossi, N. Rega, J. M. Millam, M. Klene, J. E. Knox, J. B. Cross, V. Bakken, C. Adamo, J. Jaramillo, R. Gomperts, R. E. Stratmann, O. Yazyev, A. J. Austin, R. Cammi, C. Pomelli, J. W. Ochterski, R. L. Martin, K. Morokuma, V. G. Zakrzewski, G. A. Voth, P. Salvador, J. J. Dannenberg, S. Dapprich, A. D. Daniels, Ö. Farkas, J. B. Foresman, J. V. Ortiz, J. Cioslowski and D. J. Fox, Gaussian 09, Revision A.02; Gaussian, Inc.: Pittsburgh, PA, 2009.

E. Matito, ESI-3D: Electron Sharing Indexes Program for 3D Molecular Space Partitioning. http://iqc.udg.es/ eduard/ESI; Institute of Computational Chemistry: Girona, 2006.

37. E. Matito, M. Duran and M. Solà, J. Chem. Phys., 2005, 122, 014109; Erratum íbid 2006, 125, 059901.

38. E. Matito, M. Solà, P. Salvador and M. Duran, Faraday Discuss., 2007, 135, 325-345.

39. A. D. Becke, J. Chem. Phys., 1993, 98, 5648-5652.

40. C. Lee, W. Yang and R. G. Parr, Phys. Rev. B, 1988, 37, 785789.

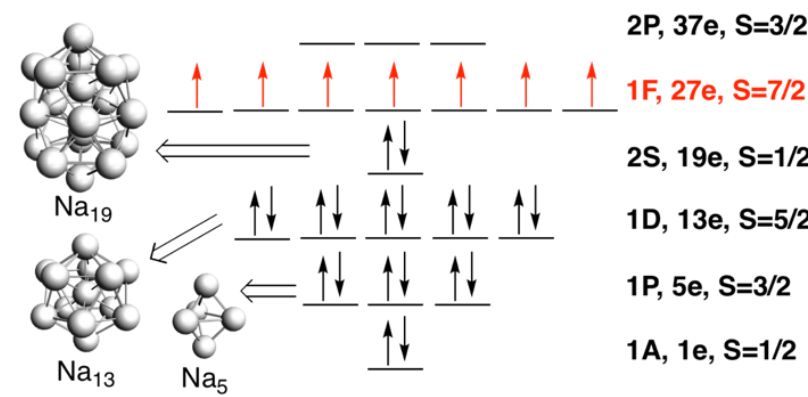

Graphic for the TOC abstract 